\title{
SYSTEMATIC REVIEW OF METHODOLOGIES FOR THE DESIGN FOR RELIABILITY IN THE PRODUCT DEVELOPMENT
}

Julia Gomes de Paula Machado (juliagmachado10@gmail.com) - Faculdade de Tecnologia, Universidade de Brasília (UnB).

Viviane Vasconcellos Ferreira Grubisic (vivianegrubisic@unb.br) - Faculdade de Tecnologia, Universidade de Brasília (UnB).

\begin{abstract}
The approach of design for reliability (DfR) is very important nowadays in the competitive scenario of industry, to guarantee the reliability of the product and also guarantee customer needs. Thus, the main objective of this paper is to collect and perform an analysis of the most recent literature about DfR. A sample of thirty-five articles was initially analyzed to arrive at the result of twelve articles to be used in this paper. As result, the main lines of research about DfR and opportunities of future research were identified.
\end{abstract}

Key words: Design; reliability; review; literature. 


\section{INTRODUCTION}

The industry nowadays is extremely competitive, in this scenario, reliable products provide a significant edge to companies in the competitive market (LEE, 2018). According to Paganin (2017), the relevance given to costumer's satisfaction have made studies on product reliability more prominent. That leads to the necessity to look at reliability at new product development, since increasing product reliability at the stage of development generates less cost than increasing its reliability after the product is already in the market.

ABNT NBR 5462 (1994) conceptualizes reliability as the probability that a component, device, system or process will perform its intended function without failure for a given time when operated correctly in a specified environment. Thus, it allows predict when it will be necessary to replace or give maintenance to determined component of the product to avoid failures.

Reliability can be considered during the entire process of a product development, however, according to O'Connor (2012), "the reliability of a product is strongly influenced by decisions made during the process design". In this way, Design for Reliability (DfR) is a process extremely important once it apply tools that allow simulate the reliability of a product even before it is ready. That brings the possibility to adapt product design according to the reliability needed and, also, reduce the production costs.

It is fundamental to adopt a Design for Reliability (DfR) approach at the stage of new product development in order to guarantee the reliability of an item at all stages of its life cycle. The amount of publications about DfR is not very extensive and it is somewhat dispersed. Thus, the main objective of this article is to collect and perform an analysis of the most recent literature. Thirty-five publications were analyzed with the purpose of identifying the theoretical foundations regarding this topic. Moreover, the main applications, challenges and limitations of DfR were identified aiming the direction for future research.

\section{RESEARCH METODOLOGY}

The aim of this review paper is to provide insights into reliable product development and answer to the research question "What the researches on design reliability approach in terms of methodology?"

To answer this question, it was adopted the part of the TEMAC model for systematic literature review which the steps are briefly presented below (MARIANO and ROCHA, 2017). 
Step 1 - Research preparation consists of answering four questions: i) What are the research key words?; ii) What is the space - time field of the research?; iii) Which databases will be used? and iv) Which knowledge areas will be adopted?

In this article, in particular, the following responses were defined to the Step 1: i) Research keywords: product design for reliability, reliability, product design for durability, reliability methodology for product design; ii) Articles published in periodicals and journals between 2013 and the first semester of 2019 were selected.; iii) The literature review was based on scientific articles from the databases of Web of Science, Scopus and Google Scholar and iv) The defined knowledge area are reliability and product design.

Step 2 - Presentation and interrelationship of data according to the TEMAC model consists of defining the types of bibliometric filters to be adopted in the article, such as analysis of the most relevant journals, analysis of journals that publish more about the subject (MARIANO and ROCHA, 2017).

For the Step 2, two types of bibliometric filters were selected in this article: Analysis of relevant journals and most cited documents from journals.

Initially, 35 articles were selected with the keywords cited above. After that, the titles and the keywords were read. From these, only those that answered the research question were selected, resulting in a total of 25 articles. The abstracts and introductions of these 25 articles were then analyzed to identify the goals, methodology adopted, main results and applications.

Thus, 15 publications that answered the research question proposed to this paper were selected. Finally, a complete reading of these articles was made, resulting in 12 articles to the elaboration of this paper. A synthesis of all the adopted process for selection and analysis of the articles is shown in Fig. 1.

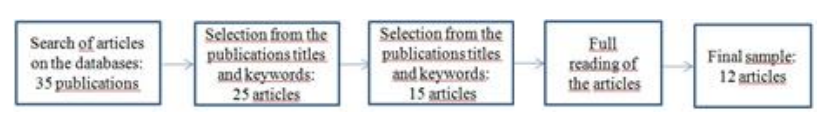

FIGURE 1 - Screening process to select the article sample. Source: Authors (2019)

\section{SYSTEMIC ANALYSIS OF THE ARTICLES}

In this section, the final sample with the twelve articles selected are analyzed. The detail of each article is based on the main concepts adopted, the methodology and the tools proposed. Moreover, the main results of each article are presented. 
A design process consists of four phases: problem definition, conceptual design, embodiment design and detailed design. LEE e PAN (2018) propose a methodology of evaluating and analyzing system reliability at its early design phases, specifically to the product's embodiment design phase. A probabilistic graphical model, called nonparametric Bayesian network (NPBN) for modeling and analyzing system reliability is introduced. The article combines the prior knowledge of component failure with expert opinions to estimate the correlations between two nodes in a NPBN, establishing a cause and effect analysis between the design solution and reliability. The objective is to decide if the current design is acceptable in terms of reaching its reliability target and, if not, how to improve it. According to the authors, this approach helps designer to adjust product design as early as possible in terms of reliability.

In the early product development stage, strategic decisions such as the amount of new technology introduction and product portfolio selection usually need to be made based on project program budget, schedule, and reliability of the new product. In this context, Li et al., (2016) proposes a multi-objective and multi-stage reliability growth planning approach with the goal of providing accurate and realistic reliability prediction in early product development stage.

A trade-off analysis among multiple product development objectives including development cost, testing time, and projected reliability are considered. This analysis provides decision makers with the insights in terms of the amount and timing of new technologies introduction, optimal testing time and units allocations, and program management efforts for growth rate improvements.

For this, the analysis for the multi-objective multi-stage formulation for reliability growth planning are searched using a modified Nondominated Sorting Genetic Algorithm (NSGA-II). The growth rate in each product-development stage and its impact on the development cost, schedule, and reliability are also discussed.

Product configuration is an important approach in customization environments. Azadeh (2015) proposes an approach to improve product configuration considering product reliability, warranty and purchasing cost in series and parallel systems as evaluation criteria to meet costumers demand. The methodology presented by Azadeh (2015) follow 10 steps as shown in Figure 2 .

The first step is to identify product's failure during production and build a Fault Tree (FT) based on customer's feedback and market requirements. Then, the next step is to identify defective 
components resulted in the top event of the FTs. The following step is to generate a random configuration, this step is used only in the first iteration. The reliability and total cost of the configuration is calculated and if it is acceptable that configuration is the result. If it is not, a Design Failure Mode and Effect Analysis (DFMEA) based on steps 2 and 3 is build and using Failure Modes and Effects Analysis (FMEA) the current configuration is improved.

The Steps 8 and 9 are to generate a new product configuration and calculate the product reliability and the total cost. Finally, evaluate the results of the previous step. If the results are acceptable there is the final configuration, if not, it is necessary to return to the DFMEA and restart the process. The loop will be stopped when the reliability and costs become acceptable. 


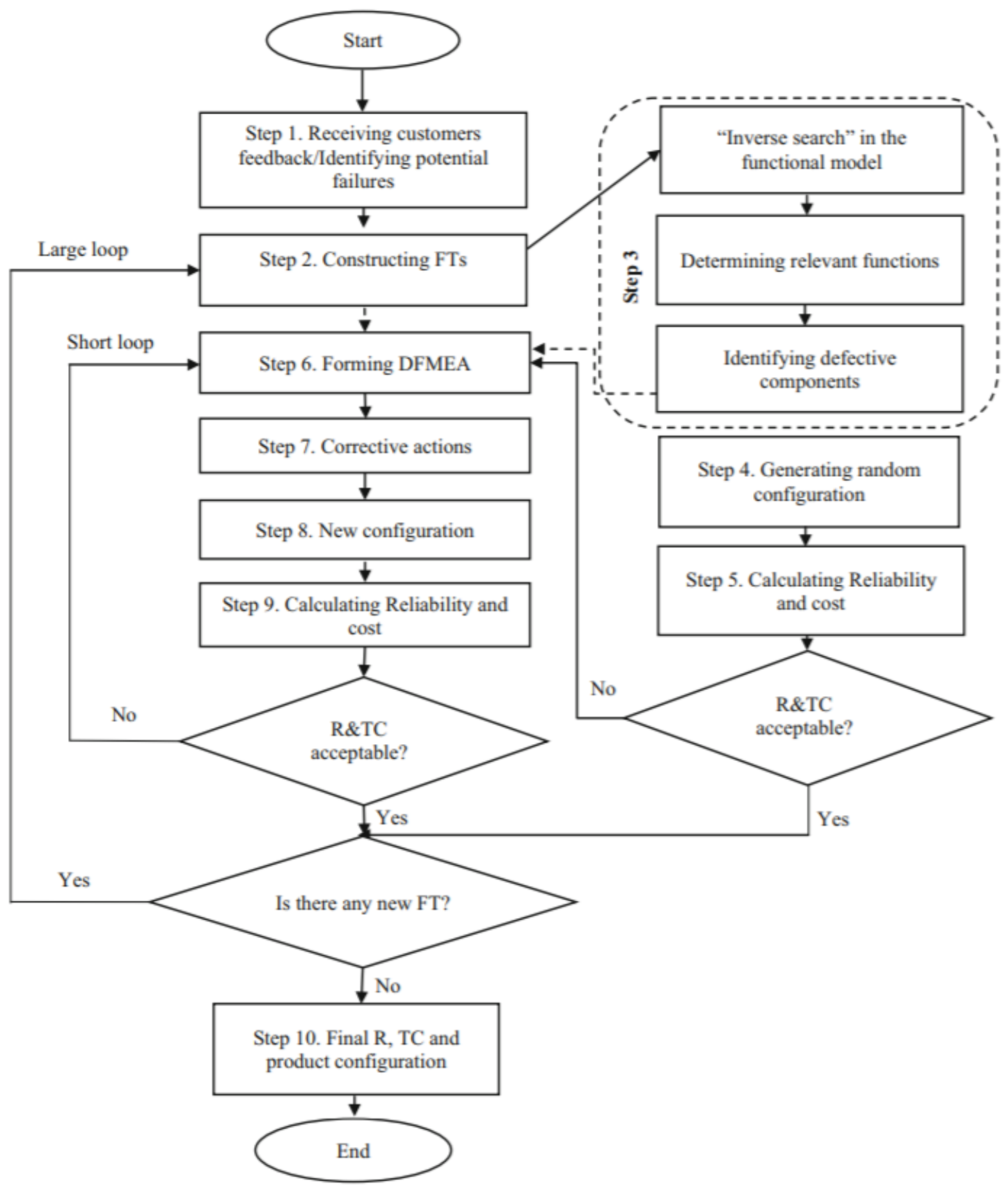

FIGURE 2 - The entire process of proposed integration approach. Source: Azadeh, A.et al. (2015)

Dror (2013) presents a methodology to determine the vital activities of the reliability program of a company through the application of the quality costs model for the strategic planning of reliability. The method used is the Quality Function Deployment (QFD) for planning and product development that specifies the customer's wants and needs. From the QFD, a matrix that expresses the desired improvement in effort failure costs according to their relative importance is deployed. 
Based on the QFD, the reliability program activities are selected using Mean Square Error (MSE) based on the Pareto rule, where $80 \%$ of the effects come from $20 \%$ of the causes. The method enables the development of a reliability program activities in order to reduce the costs of a product or system.

Raheja (2013) uses heuristics to raise points to consider in product development to ensure reliability and reduce maintenance costs.

Six heuristics were defined that must be applied to ensure a successful design, those heuristics are: (i) spend significant effort on requirements analysis; (ii) safety critical failure is not an option; (iii) measure reliability in terms of total life cycle cost, not the component cost; (iv) learn to say no to yes men; (v) don't just design for reliability, design for durability and (vi) design for prognostics to minimize surprise failures.

The first heuristic is to meet the requirements of the customer and for this it can be applied Quality functional Deployment (QFD) or house of quality to qualitatively capture customer expectations by turning them into engineering requirements for the product. Following that, it is proposed the use of Failure Modes and Effects Analysis (FMEA) and Fault Tree Analysis (FTA) to identify the failure modes analysis, once it is identified it is necessary to mitigate them through design.

The third heuristic focuses in reduce the warranty cost by increasing product reliability. According to Raheja, D (2013), 5\% increase in reliability focused development costs is likely to return a $10 \%$ reduction in the warranty cost. The following heuristic states that the schools should treat reliability as a profitmaking machine and not just a statistical tool.

Design for durability is as important as design for reliability, to achieve design for durability, it is necessary to increase the margin safety of products, this is what the fifth heuristic stands for. The last heuristic cites the importance of design for prognostics so that actions can be taken before the failure occurs.

One field that requires highly reliable products is the ammunition area. The United States Secretary of Defense mandates that all Cluster Munitions shall meet a requirement of less than $1 \%$ unexploded ordnance (UXO) (SHARP, et al., 2019). In this way, the study aims to discover potential failures and use the product redesign to mitigate these failures, thus optimizing the product design so that it meets the established reliability requirements.

The approach of design for reliability used by the authors consists in the use of the tools: (i) Reliability Block Diagram; (ii) Fault Tree Analysis; (iii) Probabilistic Analysis; (iv) Failure 
Modes Effects and Criticality Analysis (FMECA); (v) Physics of Failure Analysis (PoFA) and (vi) Design recommendations. Figure 3 illustrates the map of the reliability process proposed by the authors.

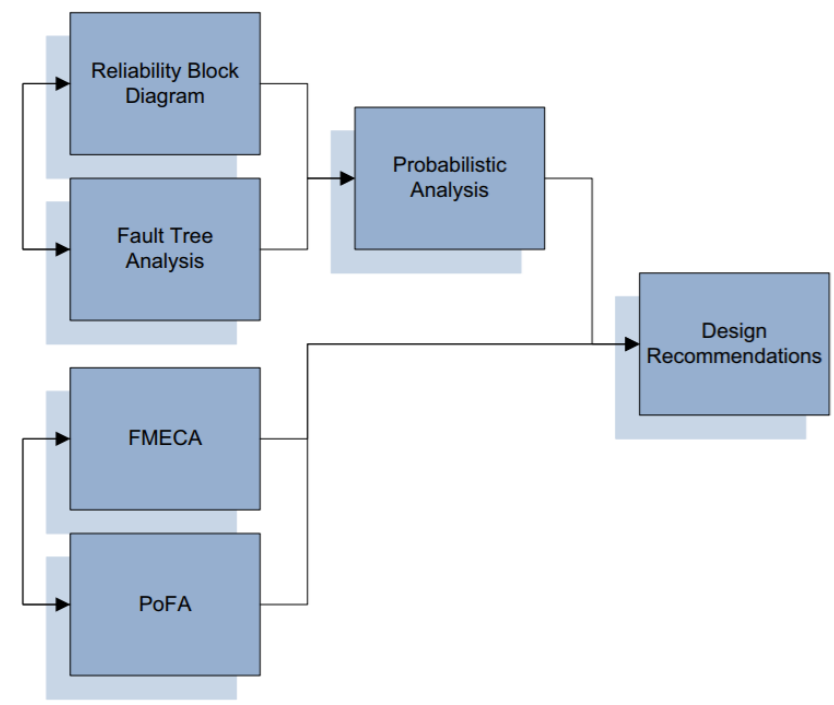

FIGURE 3 - Tailored design for reliability process map. Source: Sharp, A. et al. (2019)

Reliability Block Diagrams with associated reliability mathematical models were prepared to accurately reflect the system reliability configurations. The architecture represents the combinations of components which result in system failure. The next step is to apply the Fault Tree Analysis (FTA) to the study of the potential causes of failure for selected failure modes to increasingly detailed component levels.

Then, the Probabilistic Analysis includes the probabilistic information and deterministic modeling to calculate the feasibility of the allocations and possible failure modes that may compromise the overall system reliability.

The FMECA was used to the identification of potential failure modes within the system and the effect that the failures may have on its capability. Concomitantly the application of the FMECA, it was proposed the Physics of Failure Analysis (PoFA) is an approach to achieving reliability estimates for mechanical and electrical components that may be informed by physical testing or simulations. The combination of the tools generated the design recommendations to prevent or mitigate damage accumulated by components in order to ensure a robust design and meet life cycle requirements (SHARP et al., 2019).

GOO et al., (2017) proposes a methodology for the conceptual design of product design, considering reliability of the product in the early design stages. The methodology integrates the axiomatic design with the Failure Modes Effects and Criticality Analysis (FMECA), to obtain 
improvements in the development of a natural gas supply system. The results showed that the use of the two approaches at the early stage of development resulted in an increase in the reliability of the final product.

The axiomatic design (AD) proposed by the authors is a logical and systematic design methodology that focuses on the functional requirements of the system and allows the analysis of failure modes from existing processes. The $\mathrm{AD}$ can relate the functional requirements with design parameters. That is, while the FMECA analyzes the reliability of the system as a whole based on failure modes, providing a quantitative analysis, the axiomatic design provides a design framework that focuses on allowing the systematic implementation of the project.

The author uses the two methodologies as complementary to propose a method that provides a system with multiple failure modes and increases the reliability of the final product. Kirkire et al., (2015) propose the use of FMEA and fuzzy FMEA to analyze the risk of developing medical products aiming to increase their reliability.

The Risk Priority Number (RPN) of each risk was calculated using FMEA and fuzzy FMEA and a comparison was made between the results. Then, the risks were categorized into four categories: critical, moderate, low and insignificant risks. After this analysis, it was concluded that the use of fuzzy FMEA brings more coherent and accurate results in comparison to FMEA, to increase the reliability of the products. The Figure 4 illustrates the comparison between the two methods adopted based on the criticality of the risks.

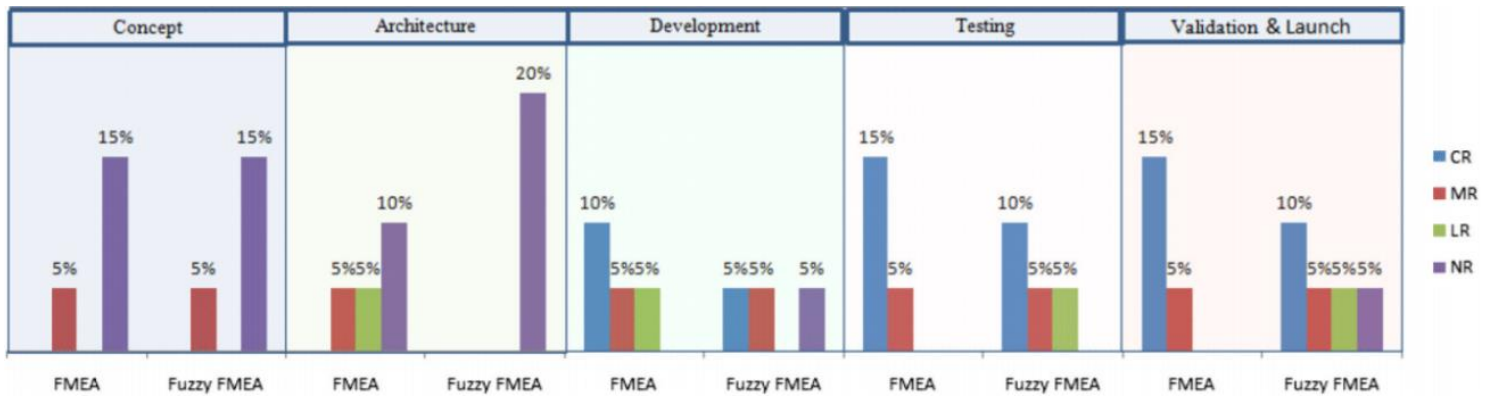

FIGURE 4 - Distribution of CRs, MRs, LRs and NRs along phases. Source: Kirkire, M. et al. (2015)

It is interesting to notice that the fuzzy FMEA prioritizes all four risks (Critical (CR), Moderate (MR), Low Risk (LR) and Negligible risk (NR)) at the Validation \& Launch stage and at the Development stage it prioritizes equally the CR, MR, NR while FMEA focuses at the Critical Risks. 
According to the article results, prioritizing Medical Product Development (MPD) process risks using fuzzy FMEA are found to be more logical as compared to traditional FMEA, since it filtered the critical risk from 40 to $25 \%$.

Designing products with high reliability while challenging, can bring great competitive advantages to the company. In this way, a study was carried out in the automotive sector considering the reliability and safety of the dry friction clutch subsystems in the product design stage, (MOHAMMAD et al., 2017)

In the article, FMEA was adopted to identify the failure mode of the subsystems. Then, the system was modeled by the reliability block diagram method, simulated by Monte Carlo simulation. Monte Carlo simulation is a statistical method that calculates probabilities heuristically using massive for a sampling of data. In this case, it can be used to calculate the reliability of the product, since it is based on statistical probabilities. After analyzing the results of the FMEA, it was concluded that the increase in the quality of the components of the subsystem as well as the addition of redundancy to the subsystem increased the system's reliability.

Accelerated Life Testing (ATL) consists of a variety of test methods for shortening the life of products or hastening the degradation of their performance. The purpose of the test is to obtain data about the life and performance of the product without having to wait for its natural degradation. In this way, the application of the test allows collecting data about the reliability of the product and improving it in a short period of time (ZAHARIA, S. M. and MARTINESCU, L., 2013).

In this way, the article uses the ALT to analyze the reliability of a sample of 10 electronic systems. A Monte Carlo Simulation model is used to study the reliability of the systems. Thus, it is possible to calculate the reliability of a given product in a shorter test time, resulting in lower costs related to testing (ZAHARIA, S. M. and MARTINESCU, L., 2013).

Cruz (2015) analyzes how the incorporation of tools such as six sigma and lean design in design of new products can increase reliability and quality. It also analyzes the impact of applying these tools to the cost of producing the products. According to the study, these new tools should be applied in a new approach to New Product Design (NPD) based on the Advanced Product and Quality Planning methodology (CRUZ, 2015).

The author proposed five steps to implement six sigma and lean design to NPD. First a developing product is selected to apply the tools, then the FMEA is applied to identify the Risk 
Priority Number in each component of the product. The third step is to perform the stacking tolerance analysis and then the analysis of manufacturing capacity. Finally, the safety factor is calculated, which increases the reliability of the product.

The article case study indicates a decrease of five points in the Risk Priority Number of the product under analysis, which indicates an increase in product reliability. In addition, there was a reduction in its cost of production (CRUZ, 2015).

Natarajan et al., (2013) also studies the applicability of the six sigma concept in NPD (new product design) in order to increase the reliability of the final product. The article proposes a method called QUARNEWSS, which means quality, reliability, new product and six sigma. The method was introduced to fill the gap in the literature regarding to a model that infuses quality and reliability in the development of new products.

QUARNEWSS model consists of thirteen which are: (i) Exposure program on the implementation of QUARNEWSS model; (ii) Exposure program on common tools and techniques; (iii) Building of training infrastructure; (iv) New product initiation; (v) New product conceptualization; (vi) New product prototyping; (vii) New product evolution; (viii) Define; (ix) Measure; (x) Analyze; (xi) Improve; (xii) Control and (xiii) Manufacture a new product.

After the case study, it was concluded that the model can be used for infusing sigma level quality and one hundred percent reliability in new products.

\section{CONCLUSION}

Design for Reliability (DfR) is shown as a very important aspect to be considered nowadays to attract more consumers. In this way, this article aimed to collect and perform an analysis of the most recent literature over the topic of DfR and answer the question: "What the researches on design for reliability approach in terms of methodology?".

During the analysis of the twelve articles, it was possible to notice that Failure Modes and Effects Analysis (FMEA) is a methodology widely used to identify failure modes. Most of the articles analyzed utilized FMEA along with another methodology, such as the Axiomatic Design which can relate the functional requirements with design parameters, to obtain some improvements at determinate system. Four out of twelve articles analyzed in this paper, utilizes FMEA as a tool to improve reliability in new product design. 
For planning product reliability at early stages of development, it was brought up the necessity of using costumers' expectations as engineering requirements for developing new products. Dror (2013) and Reheja (2013) utilized QFD for planning and develop products that attend costumers needs.

It is also seen the use of Monte Carlo Simulation to study and simulate the reliability of the systems as shown by Alvarez (2015) and Natarajan, et al. (2013).

It was possible to notice that the articles which proposes a sequence of steps to obtain the best configuration of the product in development, as shown by Sharp et al. (2018) and Zaharia (2013) follow the logic of a cycle of analysis and improvement, where the reliability of certain configuration is planned, tested, analyzed and constantly improved. As an analogy, those methodologies proposed can be referred to a PDCA cycle (Plan, Do Check and Act).

Design for reliability was explored in several applications in this paper, thus there is no restriction in where it could be applied. As future research it is recommended the development of a methodology for the DfR in the product development seeing the Industry 4.0 technology and the development of a methodology for the DfR directed to service development.

\section{REFERENCES}

ALVAREZ, J. Lean design for Six Sigma: An integrated approach to achieving product reliability and low-cost manufacturing. International Journal of Quality \& Reliability Management, Vol.32 Issue: 8, p.895-905., 2015.

AZADEH, A., SHEIKHALISHAHI, M., AGHSAMI, A. An integrated FTA-DFMEA approach for reliability analysis and product configuration considering warranty cost. German Academic Society for Production Engineering, v. 9, n. 5-6, p.635-646, 30., 2015.

DROR, S. House of Reliability Costs: Developing Reliability Program Activities. John Wiley \& Sons, p.375$380,10 ., 2013$

GOO, B., LEE, J., SEO, S., CHANG, D., CHUNG, H. Design of reliability critical system using axiomatic design with FMECA. International Journal of Naval Architecture And Ocean Engineering. Republic Of Korea, p. 1-11. 24., 2017.

KIRKIRE, M., RANE, S., JADHAV, J. Risk management in medical product development process using traditional FMEA and fuzzy linguistic approach: a case study. Journal of Industrial Engineering International, v. 11, n. 4, p.595-611, 27., 2015.

LEE, D., PAN, R. A nonparametric Bayesian network approach to assessing system reliability at early design stages. Elsevier. Arizona, p. 57-66. 17., 2017.

LI, Z., MOBIN, M., KEYSER, T. Multi Objective and MultiStage Reliability Growth Planning in Early Product Development Stage. IEEE Transactions On Reliability, v. 2, n. 65, p.769-781., 2016.

MARIANO, A., SANTOS, M. Revisão da Literatura: Apresentação de uma Abordagem Integradora. Aedem International Conference - Economy, Business And Uncertainty: Ideas For A European And Mediterranean Industrial Policy?, Reggio di Calabria, p.427-443., 2017.

M. Natarajan, V. Senthil, S.R. Devadasan, N. Vijay Mohan, N.M. Sivaram, (2013) "Quality and reliability in new product development: A case study in compressed air treatment products manufacturing company", Journal of Manufacturing Technology Management, Vol. 24 Issue: 8, pp.1143-1162. 
O’CONNOR, P.; KLEYNER, A. Practical Reliability Engineering. Wiley, 2012.

PAGANIN, L., BORSATO, M. A Critical Review of Design for Reliability - A Bibliometric Analysis and Identification of Research Opportunities. Procedia Manufacturing, [s.l.], v. 11, p.1421-1428, 2017. Elsevier BV

POURGOL-MOHAMMAD, Mohammad et al. Design for reliability of automotive systems; case study of dry friction clutch. International Journal Of System Assurance Engineering And Management, [s.1.], v. 8, n. 3, p.572-583, 11 jul. 2017. Springer Nature. http://dx.doi.org/10.1007/s13198-017-0644-2.

REHEJA, D. Heuristics for Design for Reliability for Electrical and Electronic Products. IEEE Practical Innovations, p. 63-66, 2013.

SHARP, A., ANDRADE, J., RUFFINI, N. Design for reliability for the high reliability fuze. Elsevier, Nova Jersey, V. 181, p.54-61, 2018

ZAHARIA, S., MARTINESCU, I. "Improving product reliability under accelerated life testing using monte carlo simulation”. Scientific Bulletin Of The „petruMaior”, TîrguMure?, v. 10, n. 2, p.45-48, 2013. 